\title{
Efficacy of alphacypermethrin-treated high density polyethylene mesh applied to jet stalls housing horses against Culicoides biting midges in South Africa
}

P.C. Page ${ }^{a, *}$, K. Labuschagne ${ }^{b}$, G.J. Venter ${ }^{b}$, J.P. Schoeman ${ }^{\text {a }}$, A.J. Guthrie ${ }^{c}$

\footnotetext{
a Department of Companion Animal Clinical Studies, Faculty of Veterinary Science, University of Pretoria, Private Bag X04, Onderstepoort 0110, South Africa

${ }^{\mathrm{b}}$ PVVD, ARC-Onderstepoort Veterinary Institute, Private Bag X05, Onderstepoort 0110, South Africa

${ }^{c}$ Equine Research Centre, Faculty of Veterinary Science, University of Pretoria, Private Bag X04, Onderstepoort 0110, South Africa

* Corresponding author:

Patrick Page: Email: patrick.page @ up.ac.za. Tel.: +27 12 5298261. Mobile: +27 825113410
}

\begin{abstract}
The efficacy of alphacypermethrin-treated high density polyethylene (HDPE) mesh applied to jet stalls against Culicoides biting midges (Diptera: Ceratopogonidae) was determined by mechanical aspiration of midges from horses and using Onderstepoort 220V downdraught black light traps in four blocks of a 3 x 2 randomised design under South African field conditions. The alphacypermethrintreated HDPE mesh applied to the stall significantly $(P=0.008)$ reduced the number of Culicoides midges, predominantly Culicoides (Avaritia) imicola Kieffer, mechanically aspirated from horses housed in the stall. The mesh reduced the Culicoides midge attack rate in the treated stall compared to the untreated stall and a sentinel horse by 6 times and 14 times, respectively. The number of Culicoides midges and C. imicola collected in light traps from the untreated and alphacypermethrin HDPE mesh-treated stalls did not differ significantly $(P=0.82)$. Alphacypermethrin-treated HDPE mesh could be used to reduce exposure of horses in jet stalls to Culicoides midges, specifically $C$. imicola, and the risk of midge-borne Orbivirus transmission.
\end{abstract}

Keywords: Culicoides imicola, mechanical aspiration, light trap, pyrethroid, African horse sickness 


\section{Introduction}

Culicoides biting midges (Diptera: Ceratopogonidae) are of importance to health and trade in equids worldwide, primarily due to Orbivirus transmission (Mellor et al., 2000; Meiswinkel et al., 2004). Based on their abundance near livestock Culicoides (Avaritia) imicola Kieffer and Culicoides (Avaritia) bolitinos Meiswinkel are considered the principal vectors of African horse sickness virus (AHSV) and equine encephalosis virus (Nevill et al., 1992; Venter et al., 2002; Meiswinkel et al., 2004; Paweska and Venter, 2004) in South Africa. They are also the dominant species mechanically aspirated from horses at Onderstepoort, South Africa (Scheffer et al., 2012).

Outbreaks in northern Europe of bluetongue virus (Carpenter, 2009), and recently Schmallenberg virus (Hoffmann et al., 2012), have demonstrated the devastating effect of midge-borne viruses on naïve livestock populations. Subsequently, there has been increased concern over the risk of introduction of other midge-borne viruses, such as AHSV, and the need for evidence-based control strategies (Carpenter et al., 2008a, 2009; MacLachlan and Guthrie, 2010; Papadopoulos et al., 2010; Backer and Nodelijk, 2011; MacLachlan and Mayo, 2013; Napp et al., 2013; Robin et al., 2014). Intercontinental trade is a potential mechanism whereby viruses may be introduced into at-risk horse populations, either via movement of infected hosts or vectors (Carpenter et al., 2009; MacLachlan and Guthrie, 2010; Reiter, 2010; de Vos et al., 2012; Napp et al., 2013). Consequently the World Organisation for Animal Health (OIE) have included recommendations in the Terrestrial Animal Health Code on infection with AHSV that insecticide-treated mesh of appropriate gauge be placed over containerised systems transporting horses through regions not free of AHSV (World Organisation for Animal Health, 2013).

The use of mesh to protect stabled horses (Barnard, 1997; Meiswinkel et al., 2000) and the efficacy of insect repellents or insecticides applied to mesh surrounding light traps against Culicoides midges have been reported (Braverman and Chizov-Ginzburg, 1998; Page et al., 2009, 2014; Venter et al., 2011, 2014; Del Río et al., 2014a, b). In contrast to the proven efficacy (Lengeler, 2004) and extensive use of pyrethroid-treated mesh against mosquitoes, the use of similar material to protect 
horses against Culicoides midges has received limited attention (Carpenter et al., 2008a). Efficacy of alphacypermethrin-treated high density polyethylene (HDPE) mesh intended for protection of horses against $C$. imicola has recently been demonstrated using light traps and a bioassay (Page et al., 2014).

The objective of this study was to determine if alphacypermethrin-treated HDPE mesh applied to a commercial containerised horse transport system (jet stall) would reduce the number of Culicoides midges, particularly $C$. imicola and $C$. bolitinos, mechanically aspirated from horses housed in the stalls in the field. This will support use of the mesh to reduce risk of midge-borne Orbivirus transmission during intercontinental transport of horses.

\section{Methods}

\subsection{Study site and design}

The efficacy in reducing the number of Culicoides midges aspirated from horses housed in a noncollapsible, 3-compartment jet stall (KLM HMA, European Horse Services, Belgium) of a black, 400 denier, knitted monofilament HDPE mesh with $0.3 \mathrm{~mm}$ hole size (RK02 70\% Shade Cloth, Alnet, South Africa) treated with alphacypermethrin (Fendona ${ }^{\circledR} 6$, BASF Agro BV Arnhem, Switzerland) was determined in an observer blinded, randomised field study. The study was conducted at the Faculty of Veterinary Science, Onderstepoort $\left(25^{\circ} 38^{\prime} 51.42^{\prime \prime}\right.$, $28^{\circ} 10^{\prime} 45.96$ ”E, $1238 \mathrm{~m}$ above sea level) between 22 May and 5 June 2014. Comparisons between a mesh-treated and untreated jet stall, located $8.5 \mathrm{~m}$ apart to limit interference (Venter et al., 2012) in a grass paddock (58 m x $69 \mathrm{~m}$ ), were done by mechanical aspiration of midges around sunset from two horses housed in each of the stalls. Treatments were randomised in four blocks of a 3 x 2 design over 12 nights. Each block consisted of three nights where the allocated treatment was maintained for each stall. For the following block treatments were crossed over for the stalls. The same horses were housed in each stall for each block. An additional sentinel horse, in a paddock located $35 \mathrm{~m}$ from the jet stalls, was monitored concurrently by mechanical aspiration of midges. Entrance of Culicoides midges into the stalls was assessed overnight by $220 \mathrm{~V}$ down-draught Onderstepoort suction light traps equipped with $8 \mathrm{~W}, 23$ 
cm black light tubes (Venter et al., 2009). The study was approved by the Animal Ethics Committee of the University of Pretoria (Study V011-14).

Five healthy adult, female, Thoroughbred horses, mean (range) age 7 (5-13) years, and body mass 529 (463-584) $\mathrm{kg}$ were used. Two horses were housed in the outer compartment of each of the stalls overnight from 16h00-06h00 for six nights and thereafter around sunset (17h24-17h27) from 16h00$18 \mathrm{~h} 00$ for six nights. The middle compartment of each stall was left unoccupied to facilitate access for mechanical aspiration. Between data collection periods the horses were kept with their herd mates in an adjacent grassed paddock. Grass and alfalfa hay was fed ad libitum during data collection, and water was provided in buckets every $4 \mathrm{~h}$. Climatic variables (outside temperature, relative humidity, wind speed, rainfall, solar radiation) were recorded hourly using a weather station and data logger (Vantage Pro2 and Weatherlink, Davis, USA) located adjacent to the grass paddock.

\subsection{Jet stall treatment}

Each $15.5 \mathrm{~m}^{3}$ jet stall had $1.7 \mathrm{~m}^{2}$ rectangular openings above the front and rear ramps, permitting entry to Culicoides midges. The $35.2 \mathrm{~m}^{2}$ alphacypermethrin-treated HDPE mesh was custom-made to fit over the treated jet stall in a tent-like fashion, with zip connectors permitting investigator entry located at the end panels. No mesh was applied to the untreated jet stall. The treated mesh was prepared according to the insecticide manufacturer's instructions for the treatment of bed nets against mosquitoes, for a target dose of $20-40 \mathrm{mg} / \mathrm{m}^{2}$, on the day prior to each block. The mesh was immersed in $0.28 \mathrm{mg} / \mathrm{ml}$ alphacypermethrin suspension for $30 \mathrm{~min}$ and air dried overnight at $20{ }^{\circ} \mathrm{C}$ and $65 \%$ relative humidity. A new mesh was prepared for each treatment block. To counteract depletion of the alphacypermethrin on the mesh due to environmental factors the sides and end panels of the mesh were hand-sprayed at $15 \mathrm{~h} 00$ on the second and third days of each block with $12.3 \mathrm{mg} / \mathrm{m}^{2}$ of 0.28 $\mathrm{mg} / \mathrm{ml}$ alphacypermethrin suspension. Alphacypermethrin uptake was quantified by high performance liquid chromatography (HPLC) analysis of duplicate mesh samples prepared for each block and by duplicate mesh sections $(15 \times 15 \mathrm{~cm})$ attached to the sides of the stall to monitor the replenishment rate. 


\subsection{Mechanical aspiration of midges}

Midges were aspirated from horses using a customized mechanical aspirator (2820B DC Insect vacuum, BioQuip Products Inc., U.S.A.) mounted on a $12 \mathrm{~V}$ hand-held vacuum cleaner (AV1205, Black and Decker, South Africa). One side of each horse inside the stall was aspirated in a systematic manner from cranial to caudal and dorsal to ventral on the neck, back, rump and side by the same investigator. This cycle was repeated until the $2.5 \mathrm{~min}$ collection period/horse was completed. Aspiration was performed similarly on both sides of the sentinel horse for $2.5 \mathrm{~min}$ per side. The time frame for aspiration lasted from $30 \mathrm{~min}$ before to $15 \mathrm{~min}$ after sunset, allowing for two $5 \mathrm{~min}$ collection periods at each site. Horses were left undisturbed for a 30 min exposure period before the start of aspiration and for a minimum $10 \mathrm{~min}$ exposure period between aspiration cycles. The sequence of aspiration for each stall and the sentinel horse was randomised in four replicates of a $3 \mathrm{x}$ 3 Latin square design (Snedecor and Cochran, 1980) to eliminate effects due to site or occasion.

\subsection{Light trap collection of midges}

Onderstepoort suction light traps were operated inside the rear entrance of each stall, $30 \mathrm{~cm}$ from the HDPE mesh enclosing the stall and $2 \mathrm{~m}$ above ground level. White polyester netting (hole size $2 \mathrm{~mm}$ ) was placed around the entrance portal of each light trap to exclude larger insects. The traps were operated from 18h00 (after sunset) to 06h00 (after sunrise); light trap collections and aspiration were therefore not done simultaneously. Catches were made into $500 \mathrm{ml}$ plastic beakers containing $200 \mathrm{ml}$ $0.5 \%$ Savlon $^{\circledR}$ (Johnson and Johnson, South Africa) and water solution.

\subsection{Culicoides midge identification}

Insects collected were stored in $70 \%$ ethanol prior to Culicoides midge segregation according to species morphology (unpublished wing pattern keys, PVVD, ARC-Onderstepoort Veterinary Institute), sex and parity status (Dyce, 1969) as nulliparous (unpigmented), parous (pigmented), blood fed and gravid females. Large light trap midge collections were sub-sampled (Van Ark and Meiswinkel, 1992). 


\subsection{Statistical analyses}

Statistical analyses were done using SPSS $^{\circledR}$ Statistics version 22 (IBM, USA). Aspirated midge numbers were compared between treatment groups by Kruskal-Wallis one-way ANOVA on ranks. The Mann-Whitney U test was used for pairwise comparisons. Post hoc comparisons were adjusted using the Bonferroni correction of $P$ values. When the Bonferroni correction was applied, $P<0.017$ was considered significant. Attack rate was calculated as the total number of midges aspirated from the horses at each site per minute of collection period. Biting rate was calculated as the total number of freshly blood fed midges aspirated from the horses at each site per minute of collection period.

Midge numbers from the light trap collections were natural logarithm-transformed to achieve normality. Mean numbers of Culicoides midges and C. imicola were compared between treatment groups using independent samples t-test. Homogeneity of variances was tested with Levene's test. Statistical testing was conducted at the $5 \%$ level of significance.

Pearson's Chi-square statistic was used to test the proportion of $C$. imicola in relation to the other Culicoides species for independence from treatment. Species diversity for each site was calculated with the Shannon-Wiener index (Al Young Studios, 2012).

\section{Results}

\subsection{Mechanical aspiration of midges}

A total of 499 Culicoides midges were aspirated from four horses housed in two stalls and one sentinel horse during 36 collections made around sunset for 12 nights. C. imicola was the dominant species and comprised $96.6 \%$ of midges aspirated, followed by C. bolitinos (3.2\%) (Table 1). One other species, C. (Culicoides) magnus Colaço, was aspirated. The majority of C. imicola aspirated were nulliparous (70.3\%), followed by parous, blood fed and gravid females, with no males (Table 2). The proportion of $C$. imicola in relation to the other species collected by aspiration was $98.8 \%$ for the stalls combined and $95.6 \%$ for the sentinel horse, and was not significantly different between 
Table 1. Summary of Culicoides species collected by mechanical aspiration from horses and in black light traps operated inside two jet stalls for 12 nights between 22 May and 5 June 2014.

\begin{tabular}{|c|c|c|}
\hline & Mechanical aspiration & Light trap \\
\hline & Total (\%) & Total (\%) \\
\hline C. imicola & $482(96.6)$ & $36075(99.1)$ \\
\hline C. bolitinos & $16(3.2)$ & $173(0.5)$ \\
\hline C. magnus & $1(0.2)$ & $46(0.1)$ \\
\hline C. zuluensis & & $38(0.1)$ \\
\hline C. gulbenkiani & & $21(0.1)$ \\
\hline C. pycnostictus & & $17(<0.1)$ \\
\hline C. nevilli & & $13(<0.1)$ \\
\hline C. brucei & & $12(<0.1)$ \\
\hline C. leucostictus & & $9(<0.1)$ \\
\hline C. enderleini & & $7(<0.1)$ \\
\hline C. nivosus & & $1(<0.1)$ \\
\hline Total & 499 & 36412 \\
\hline
\end{tabular}

treatments $\left(X^{2}=3.384\right.$, d.f. $\left.=1, P=0.066\right)$. Species diversity was lower in the jet stalls $\left(H^{\prime}=0.1\right)$ than on the sentinel horse $\left(H^{\prime}=0.3\right)$ (Table 2$)$.

The alphacypermethrin-treated HDPE mesh applied to the stall significantly $(P=0.008)$ reduced the number of Culicoides midges, predominantly $C$. imicola, mechanically aspirated from horses housed in the stalls, and reduced the Culicoides midge attack rate compared to the untreated stall and sentinel horse by 6 times and 14 times, respectively (Table 2). Whilst the number of Culicoides midges aspirated in the treated stall was significantly $(P<0.001)$ lower than the number of midges aspirated from the sentinel horse, the number of midges aspirated in the untreated stall did not differ significantly after Bonferroni correction $(P=0.099)$ from the sentinel horse (Table 2$)$. 
Table 2. Culicoides midges, $C$. imicola, and $C$. bolitinos collected during $5 \mathrm{~min}$ of mechanical aspiration of two horses housed inside a jet stall with alphacypermethrin-treated $\left(31.8-33.7 \mathrm{mg} / \mathrm{m}^{2}\right) \mathrm{HDPE}$ mesh, two horses housed inside an untreated jet stall and a sentinel horse, around sunset for 12 nights between 22 May and 5 June 2014.

\begin{tabular}{|c|c|c|c|c|c|c|c|}
\hline & & \multicolumn{4}{|c|}{ Jet stall } & \multicolumn{2}{|c|}{ Sentinel horse } \\
\hline & & \multicolumn{2}{|c|}{$\begin{array}{l}\begin{array}{l}\text { Alphacypermethrin-treated HDPE } \\
\text { mesh }\end{array}\end{array}$} & \multicolumn{2}{|c|}{ Untreated HDPE mesh } & \multirow[b]{2}{*}{$\mathrm{n}$} & \multirow[b]{2}{*}{$\%$} \\
\hline & & $\mathrm{n}$ & $\%$ & $\mathrm{n}$ & $\%$ & & \\
\hline \multirow[t]{10}{*}{ C. imicola } & Total & 26 & 100 & 133 & 98.5 & 323 & 95.6 \\
\hline & Median & $0^{\mathrm{a}}$ & & $4^{\mathrm{b}}$ & & $9^{\mathrm{b}}$ & \\
\hline & Range & $0-7$ & - & $0-30$ & & $0-59$ & 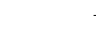 \\
\hline & Attack rate & 0.2 & - & 1.1 & - & 2.7 & - \\
\hline & Biting rate & 0 & - & 0 & - & 0.1 & . \\
\hline & $\begin{array}{l}\text { Nulliparous } \\
\mathrm{P}\end{array}$ & $\begin{array}{r}17 \\
0\end{array}$ & $\begin{array}{l}65.4 \\
346\end{array}$ & $\begin{array}{l}90 \\
42\end{array}$ & $\begin{array}{l}67.7 \\
3.2\end{array}$ & $\begin{array}{r}232 \\
80\end{array}$ & $\begin{array}{l}71.8 \\
24.8\end{array}$ \\
\hline & Parous & 9 & 34.6 & 43 & 32.3 & 80 & 24.8 \\
\hline & Gravid & 0 & 0 & 0 & 0 & 1 & 0.3 \\
\hline & Blood fed & 0 & 0 & 0 & 0 & 10 & 3.1 \\
\hline & Male & 0 & 0 & 0 & 0 & 0 & 0 \\
\hline \multirow[t]{10}{*}{ C. bolitinos } & Total & 0 & 0 & 2 & 1.5 & 14 & 4.1 \\
\hline & Median & $0^{\mathrm{a}}$ & - & $0^{\mathrm{a}, \mathrm{b}}$ & - & $0^{\mathrm{b}}$ & - \\
\hline & Range & $0-0$ & - & $0-1$ & - & $0-4$ & - \\
\hline & Attack rate & 0 & - & 0.02 & - & 0.1 & - \\
\hline & Biting rate & 0 & - & 0 & - & 0 & - \\
\hline & $\begin{array}{l}\text { Nulliparous } \\
\text { p }\end{array}$ & 0 & 0 & 1 & 50.0 & 10 & 71.4 \\
\hline & Parous & 0 & 0 & 1 & 50.0 & 4 & 28.6 \\
\hline & Gravid & 0 & 0 & 0 & 0 & 0 & 0 \\
\hline & Blood fed & 0 & 0 & 0 & 0 & 0 & 0 \\
\hline & Male & 0 & 0 & 0 & 0 & 0 & 0 \\
\hline Culicoides midges & Total & 26 & - & 135 & - & 338 & - \\
\hline \multirow[t]{5}{*}{ midges } & Median & $0^{\mathrm{a}}$ & - & $4^{\mathrm{b}}$ & - & $9^{\mathrm{b}}$ & - \\
\hline & Range & $0-7$ & - & $0-30$ & - & $0-63$ & - \\
\hline & Attack rate & 0.2 & - & 1.1 & - & 2.8 & - \\
\hline & Biting rate & 0 & - & 0 & - & 0.1 & - \\
\hline & $\begin{array}{l}\text { Shannon-Wiener } \\
\text { index }\end{array}$ & - & & 0.1 & & 0.3 & \\
\hline
\end{tabular}


Table 3. Culicoides midges, C. imicola, and C. bolitinos collected by black light traps inside a jet stall fitted with alphacypermethrintreated $\left(31.8-33.7 \mathrm{mg} / \mathrm{m}^{2}\right)$ HDPE mesh or an untreated jet stall, operated overnight for 12 nights between 22 May and 5 June 2014.

\begin{tabular}{|c|c|c|c|c|c|}
\hline & & \multicolumn{4}{|c|}{ Jet stall } \\
\hline & & \multicolumn{2}{|c|}{ Alphacypermethrin-treated HDPE mesh } & \multicolumn{2}{|c|}{ Untreated HDPE mesh } \\
\hline & & $\mathrm{n}$ & $\%$ & $\mathrm{n}$ & $\%$ \\
\hline \multirow[t]{7}{*}{ C. imicola } & Total & 17026 & 99.0 & 19049 & 99.1 \\
\hline & Mean \pm S.E. & $1419 \pm 617$ & - & $1587 \pm 646$ & - \\
\hline & $\begin{array}{l}\text { Nulliparous } \\
\mathbf{n}\end{array}$ & $\begin{array}{c}13040 \\
\text { תonn }\end{array}$ & $\begin{array}{l}76.6 \\
n 1\end{array}$ & $\begin{array}{c}14668 \\
\text { 1ก1ก }\end{array}$ & $\begin{array}{l}77.0 \\
n 1\end{array}$ \\
\hline & Parous & $\begin{array}{r}3809 \\
11\end{array}$ & 22.4 & 4212 & 22.1 \\
\hline & Gravid & 11 & 0.1 & 23 & 0.1 \\
\hline & Blood fed & 153 & 0.9 & 121 & 0.6 \\
\hline & Male & 13 & 0.1 & 25 & 0.1 \\
\hline \multirow[t]{7}{*}{ C. bolitinos } & Total & 107 & 0.6 & 66 & 0.3 \\
\hline & Mean \pm S.E. & $9 \pm 5$ & - & $6 \pm 3$ & - \\
\hline & $\begin{array}{l}\text { Nulliparous } \\
\mathbf{n}\end{array}$ & $\begin{array}{l}68 \\
\text { no }\end{array}$ & $\begin{array}{l}63.6 \\
<<1\end{array}$ & $\begin{array}{l}20 \\
15\end{array}$ & $\begin{array}{l}30.3 \\
60.1\end{array}$ \\
\hline & Parous & 39 & 36.4 & 45 & 68.2 \\
\hline & Gravid & 0 & 0 & 1 & 1.5 \\
\hline & Blood fed & 0 & 0 & 0 & 0 \\
\hline & Male & 0 & 0 & 0 & 0 \\
\hline Other Culicoides & Total & 60 & 0.3 & 104 & 0.5 \\
\hline \multirow[t]{6}{*}{ Culicoides } & Mean \pm S.E. & $5 \pm 2$ & - & $9 \pm 7$ & - \\
\hline & $\begin{array}{l}\text { Nulliparous } \\
\mathbf{n}\end{array}$ & 34 & $\begin{array}{l}56.7 \\
117\end{array}$ & $\begin{array}{l}60 \\
11\end{array}$ & $\begin{array}{l}57.7 \\
2 \times 1\end{array}$ \\
\hline & Parous & 25 & 41.7 & 41 & 39.4 \\
\hline & Gravid & 1 & 1.7 & 1 & 1 \\
\hline & Blood fed & 0 & 0 & 0 & 0 \\
\hline & Male & 0 & 0 & 2 & 1.9 \\
\hline Total Culicoides & Total & 17193 & - & 19219 & . \\
\hline \multirow[t]{2}{*}{ Culicoides } & Mean \pm S.E. & $1433 \pm 623$ & - & $1602 \pm 653$ & 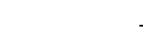 \\
\hline & $\begin{array}{l}\text { Shannon Wiener } \\
\text { index }\end{array}$ & 0.1 & - & 0.1 & . \\
\hline
\end{tabular}




\subsection{Light trap collection of midges}

A total of 36412 Culicoides midges, comprising 11 species, were collected in 24 collections made over 12 nights from two light traps operated simultaneously. C. imicola was the most abundant species and comprised $99.1 \%$ of midges collected, followed by C. bolitinos (0.5\%), and C. magnus $(0.1 \%)$ (Table 1$)$. The majority of $C$. imicola collected were nulliparous $(76.8 \%)$, followed by parous (22.2\%), blood fed $(0.8 \%)$ and gravid $(0.1 \%)$ females, and males $(0.1 \%)$ (Table 3$)$.

The mean number of both Culicoides midges and $C$. imicola collected in the light traps from the untreated and alphacypermethrin HDPE mesh-treated stalls did not differ significantly $(P=0.82)$ (Table 3). The proportion of $C$. imicola in relation to the other species collected in the light traps was 99\% for both the untreated stall and alphacypermethrin HDPE mesh-treated stall, and was not significantly different between treatments $\left(X^{2}=0.745\right.$, d.f. $\left.=1, P=0.388\right)$. Species diversity was similar in the treated $\left(H^{\prime}=0.1\right)$ and untreated jet stall $\left(H^{\prime}=0.1\right)$ (Table 3$)$.

The mean \pm S.D. alphacypermethrin uptake by the treated HDPE meshes as determined by HPLC analysis on the first, second and third day of each block was $33.7 \pm 4.7,32.3 \pm 2.8,31.8 \pm 7.8 \mathrm{mg} / \mathrm{m}^{2}$, within the target range of $20-40 \mathrm{mg} / \mathrm{m}^{2}$. The mean \pm S.D. outside temperature, relative humidity, wind speed and solar radiation during the data collection were $13.3 \pm 0.5^{\circ} \mathrm{C}, 67 \pm 7.1 \%, 1.1 \pm 1.1 \mathrm{~km} / \mathrm{h}$ and $140.6 \pm 13 \mathrm{~W} / \mathrm{m}^{2}$, respectively, with no rain recorded.

\section{Discussion}

The alphacypermethrin-treated HDPE mesh had a significant effect in reducing the number of Culicoides midges, predominantly $C$. imicola, mechanically aspirated around sunset from horses housed in jet stalls under field conditions. A corresponding reduction in the midge attack rate on horses housed in the treated stall compared to the untreated stall and the sentinel horse was shown. In addition, a nil biting rate on horses in both the treated and untreated jet stalls, along with a considerably lower biting rate compared to attack rate for the sentinel horse was determined. 
Aspiration of midges from bait animals is considered more reliable for assessment of treatment efficacy (Mullens, et al., 2010) and for gauging midge attack and biting rates (Carpenter et al., 2008b; Gerry et al., 2009; Scheffer et al., 2012; Viennet et al., 2012; Kirkeby et al., 2013; Elbers and Meiswinkel, 2014). The attraction of insects to a light is an artificial response and different cues are involved in the attraction of Culicoides midges to hosts than towards light traps. The time frame selected for mechanical aspiration in the present study coincided with the period around sunset when Culicoides midges have been shown to attack horses (Braverman, 1988; van der Rijt et al., 2008) and was conducted during the autumn months where peak numbers of midges have been aspirated from horses in the area (Scheffer et al., 2012). Consequently, the attack rate for $C$. imicola on the sentinel horse in the present study $(2.7 / \mathrm{min})$ was similar to the attack rate $(2.3 / \mathrm{min})$ reported when an AHSV infection rate of $0.43 \%$ was detected in aspirated midges (Scheffer et al., 2012). Furthermore, predominantly non-blood fed unpigmented (nulliparous) and parous pigmented (parous) females i.e. females searching for a blood meal, mainly $C$. imicola and $C$. bolitinos, which have been implicated as AHSV vectors (Nevill et al., 1992; Meiswinkel et al., 2004) were aspirated. Similarly, C. magnus is also considered as having a high potential vector rating (Nevill et al., 1992) and was previously shown to be susceptible to infection with AHSV (Paweska et al., 2003). The results obtained for the mesh are thus applicable to AHSV control and support the recommended use of insecticide-treated mesh placed over containerised horse transport systems in regions not free of AHSV to reduce the risk of AHSV introduction via intercontinental trade (World Organisation for Animal Health, 2013). Indeed, use of mesh could reduce the risk of AHSV-transmission to naïve horses during outbreaks of AHSV. Likewise, mesh could be used to reduce the risk of naïve midges feeding on AHSV-infected horses, as an alternative to immediate culling of suspected infected horses in non-endemic regions, along with other control measures.

Although fewer midges were collected in the light trap in the treated jet stall the reduction in numbers did not attain significance. This is in contrast to a screening study with the alphacypermethrin-treated HDPE mesh where a significant, 7-fold reduction in midge numbers was reported for a treated light 
trap (Page et al., 2014). Likewise, Del Río et al. (2014a,b) found no significant reduction in the number of Culicoides midges collected in light traps treated with cypermethrin or deltamethrin mesh. Potential reasons for the lack of significant reduction in the number of midges collected in the light trap inside the treated jet stall are related to absence of an immediate knockdown effect of the treated mesh i.e. the midges may have entered the light trap located adjacent to the mesh before being incapacitated. The relatively large mesh hole size, selected so as not to compromise stall ventilation, may not have allowed sufficient midge surface area contact with insecticide (Del Río et al., 2014a), and the midge contact time with the mesh, likely shorter than bioassay contact time (Page et al., 2014), may have been insufficient for immediate knockdown.

Increased mortality rates in midges collected in light traps have been determined after contact with insecticide treated nets (Calvete et al., 2010; Del Río et al., 2014b). Unfortunately the mortality rate of midges collected in light traps in the present study was not investigated, therefore the degree of incapacitation of midges that were able to enter the light trap after passing through the treated mesh is unknown. Nonetheless, during contact bioassays with the alphacypermethrin-treated mesh midge mortality was assessed and observed from 5 min post-exposure (Page et al., 2014), and signs of intoxication and mortality were observed 6 min post-exposure to a deltamethrin-treated mesh (Del Río et al., 2014b). It is considered likely, based on the significant reduction in attack rate determined by aspiration, that the host-seeking ability of the midges (and hence potential for viral transmission) was adversely affected soon after contact with the mesh. The exact interval between contact with alphacypermethrin-treated mesh and onset of midge intoxication having an adverse effect on hostseeking ability is unknown, however. The light trap results highlight the importance of aspiration of midges from bait animals for confirmation of treatment efficacy (Mullens, et al., 2010).

Species richness was greater in the light trap compared to mechanical aspiration, with $C$. imicola predominant for both collection methods. Similar to a previous comparison (Scheffer et al., 2012), a greater proportion of C. bolitinos, an endophilic AHSV-vector (Nevill et al., 1992; Meiswinkel et al., 2004; Meiswinkel et al., 2000), was collected by mechanical aspiration than in the light trap. A source 
of possible variability in the limited species aspirated is the body region sampled, because Culicoides species attack different body regions (Braverman, 1988) and the present study focused on the dorsal aspects favoured by $C$. imicola. Species diversity was similar between both light traps, but was greater for aspiration from the sentinel horse compared to inside the jet stalls, likely due to potential exophilic/ endophilic species preferences.

The alphacypermethrin formulation used is recommended by the World Health Organization Pesticide Evaluation Scheme for treatment of mosquito nets, and efficacy and human safety has been demonstrated for malaria control (Ansari and Razdan, 2003; Banek et al., 2010). The alphacypermethrin uptake by the HDPE meshes was within the selected target range (Page et al., 2014), and remained within range with daily replenishment. No rain was recorded during the study period however, so customised replenishment rates may be required under different climatic conditions, particularly if re-use of the mesh is desired.

In conclusion, standardised control measures such as those recommended by the OIE for AHSV (World Organisation for Animal Health, 2013) should be implemented to ensure the safe transportation of equids, especially if these animals are being moved through known AHSV infected areas or areas with unknown risk. Alphacypermethrin-treated HDPE mesh could be used to reduce exposure of horses to Culicoides midges, specifically $C$. imicola, and the risk of midge-borne Orbivirus transmission during transport in jet stall containers. Similarly, the alphacypermethrintreated mesh could also be applied to stable openings (Meiswinkel et al., 2000) to reduce the midge attack rate during AHSV outbreaks. Although a significant reduction in the number of midges attacking horses was demonstrated the alphacypermethrin-treated mesh was not $100 \%$ effective, therefore further investigation of use of the mesh in conjunction with additional control measures such as insecticide/ repellent applied to horses (Papadopoulos et al., 2010), or with aerosol insecticide dispensers operated inside jet stalls, is required. 


\section{Acknowledgments}

We thank T. Thovokale, A. Schantz, W. Mbethe, L. Mlisa, M. Badenhorst, C. Matjiane and S. Makhubela for assistance with data collection. The Equine Research Centre, Mary Slack and Daughters Foundation, and the National Research Foundation (Grant 89686) are acknowledged for funding. Hobday Equestrian Enterprises International Horse Transport and European Horse Services are acknowledged for use of KLM Cargo jet stalls.

\section{Conflict of interest statement}

The authors declare no conflict of interest.

\section{References}

Al Young $\quad$ Studios, 2014 Biodiversity calculator, available at: http://alyoung.com/labs/biodiversity_calculator.html (accessed 19.09.14).

Ansari, M.A., Razdan, R.K., 2003. Bio-efficacy and operational feasibility of alphacypermethrin (Fendona) impregnated mosquito nets to control rural malaria in northern India. J. Vector Dis. 40, 33-42.

Backer, J.A., Nodelijk, G., 2011. Transmission and control of African horse sickness in The Netherlands: a model analysis. PLoS ONE 6, e23066.

Banek, K., Kilian, A., Allan, R., 2010. Evaluation of Interceptor long-lasting insecticidal nets in eight communities in Liberia. Malaria J. 9, 84.

Barnard, B.J.H., 1997. Some factors governing the entry of Culicoides spp. (Diptera: Ceratopogonidae) into stables. Onderstepoort J. Vet. Res. 64, 227-233.

Braverman, Y., 1988. Preferred landing sites of Culicoides species (Diptera: Ceratopogonidae) on a horse in Israel and its relevance to summer seasonal recurrent dermatitis (sweet itch). Equine Vet. J. 20, 426429.

Braverman, Y., Chizov-Ginzburg, A., 1998. Duration of repellency of various synthetic and plant-derived preparations for Culicoides imicola, the vector of African horse sickness virus. Arch. Vir. S. 14, 165174. 
Calvete, C., Estrada, R., Miranda, M.A., Del Río, R., Borrás, D., Beldron, F.J., Martínez, A., Calvo, A.J., Lucientes, J., 2010. Protection of livestock against bluetongue virus vector Culicoides imicola using insecticide-treated netting in open areas. Med. Vet. Entomol. 24, 169-175.

Carpenter, S., Mellor, P.S., Torr, S.J., 2008a. Control techniques for Culicoides biting midges and their application in the U.K. and northwestern Palaearctic. Med. Vet. Entomol. 22, 175-187.

Carpenter, S., Szmaragd, C., Barber, J., Labuschagne, K., Gubbins, S., Mellor, P., 2008b. An assessment of Culicoides surveillance techniques in northern Europe: have we underestimated a potential bluetongue virus vector? J. Appl. Ecol. 45, 1237-1245.

Carpenter, S., Wilson, A., Mellor, P.S., 2009. Culicoides and the emergence of bluetongue virus in northern Europe. Trends Microbiol. 17, 172-178.

de Vos, C.J., Hoek, C.A., Nodelijk, G., 2012. Risk of introducing African horse sickness virus into the Netherlands by international equine movements. Prev. Vet. Med. 106, 108-122.

Del Río, R., Barceló, C., Lucientes, J., Miranda, M.A., 2014a. Detrimental effect of cypermethrin treated nets on Culicoides populations (Diptera; Ceratopogonidae) and non-targeted fauna in livestock farms. Vet. Parasitol. 199, 230-234.

Del Río, R., Barceló, C., Paredes-Esquivel, C., Lucientes, J., Miranda, M.A., 2014b. Susceptibility of Culicoides species biting midges to deltamethrin-treated nets as determined under laboratory and field conditions in the Balearic Islands, Spain. Med. Vet. Entomol., 10.

Dyce, A.L., 1969. The recognition of nulliparous and parous Culicoides (Diptera: Ceratopogonidae) without dissection. J. Aust. Entomol. Soc. 8, 11-15.

Elbers, A.R., Meiswinkel, R., 2014. Culicoides (Diptera: Ceratopogonidae) host preferences and biting rates in the Netherlands: Comparing cattle, sheep and the black-light suction trap. Vet Parasitol. 205, 330-337.

Gerry, A.C., Monteys, V.S., Moreno Vidal, J.O., Francino, O., Mullens, B.A., 2009. Biting rates of Culicoides midges (Diptera: Ceratopogonidae) on sheep in northeastern Spain in relation to midge capture using UV light and carbon dioxide-baited traps. J. Med. Entomol. 46, 615-624.

Hoffmann, B., Scheuch, M., Hoper, D., Jungblut, R., Holsteg, M., Schirrmeier, H., Eschbaumer, M., Goller, K.V., Wernike, K., Fischer, M., Breithaupt, A., Mettenleiter, T.C., Beer, M., 2012. Novel Orthobunyavirus in Cattle, Europe, 2011. Emerg. Infect. Dis. 18, 469-472. 
Kirkeby, C., Græsbøll, K., Stockmarr, A., Christiansen, L.E., Bødker, R., 2013. The range of attraction for light traps catching Culicoides biting midges (Diptera: Ceratopogonidae). Parasit. Vectors. 6:67. doi: 10.1186/1756-3305-6-67., 67-6.

Lengeler, C., 2004. Insecticide-treated bed nets and curtains for preventing malaria. Cochrane DB. Syst. Rev. 2, CD000363.

MacLachlan, N.J., Guthrie, A.J., 2010. Re-emergence of bluetongue, African horse sickness, and other orbivirus diseases. Vet. Res. 41, 35 .

MacLachlan, N.J., Mayo, C.E., 2013. Potential strategies for control of bluetongue, a globally emerging, Culicoides-transmitted viral disease of ruminant livestock and wildlife. Antiviral Res. 99, 79-90.

Meiswinkel, R., Baylis, M., Labuschagne, K., 2000. Stabling and the protection of horses from Culicoides bolitinos (Diptera: Ceratopogonidae), a recently identified vector of African horse sickness. Bull. Entomol. Res. 90, 509-515.

Meiswinkel, R., Venter, G.J., Nevill, E.M., 2004. Vectors: Culicoides spp. In: Coetzer, J.A.W., Tustin, R.C. (Eds.), Infectious Diseases of Livestock. Oxford University Press, Cape Town, pp. 93-136.

Mellor, P.S., Boorman, J., Baylis, M., 2000. Culicoides biting midges: their role as arbovirus vectors. Annu. Rev. Entomol. 45, 307-340.

Mullens, B.A., Gerry, A.C., Monteys, V.S., Pinna, M., González, A., 2010. Field studies on Culicoides (Diptera: Ceratopogonidae) activity and response to deltamethrin applications to sheep in northeastern Spain. J. Med. Entomol. 47, 106-110.

Napp, S., García-Bocanegra, I., Pagès, N., Allepuz, A., Alba, A., Casal, J., 2013. Assessment of the risk of a bluetongue outbreak in Europe caused by Culicoides midges introduced through intracontinental transport and trade networks. Med. Vet. Entomol. 27, 19-28.

Nevill, E.M., Venter, G.J., Edwardes, M., 1992. Potential Culicoides vectors of livestock orbivirus. In: Walton, T.E., Osburn, B.I. (Eds.), Bluetongue, African Horse Sickness, and Related Orbiviruses. CRC Press, Boca Raton, Florida, pp. 306-313.

Page, P.C., Labuschagne, K., Nurton, J.P., Venter, G.J., Guthrie, A.J., 2009. Duration of repellency of N,Ndiethyl-3-methylbenzamide, citronella oil and cypermethrin against Culicoides species when applied to polyester mesh. Vet. Parasitol. 163, 105-109. 
Page, P.C., Labuschagne, K., Venter, G.J., Schoeman, J.P., Guthrie, A.J., 2014. Field and in vitro insecticidal efficacy of alphacypermethrin-treated high density polyethylene mesh against Culicoides biting midges in South Africa. Vet. Parasitol. 203, 184-188.

Papadopoulos, E., Rowlinson, M., Bartram, D., Carpenter, S., Mellor, P., Wall, R., 2010. Treatment of horses with cypermethrin against the biting flies Culicoides nubeculosus, Aedes aegypti and Culex quinquefasciatus. Vet. Parasitol. 169, 165-171.

Paweska, J.T., Prinsloo, S., Venter, G.J., 2003. Oral susceptibility of South African Culicoides species to liveattenuated serotype-specific vaccine strains of African horse sickness virus (AHSV). Med. Vet. Entomol. 17, 436-447.

Paweska, J.T., Venter, G.J., 2004. Vector competence of Culicoides species and the seroprevalence of homologous neutralizing antibody in horses for six serotypes of equine encephalosis virus (EEV) in South Africa. Med. Vet. Entomol. 18, 398-407.

Reiter, P., 2010. The standardised freight container: vector of vectors and vector-borne diseases. Rev. Sci. Tech. $29,57-64$.

Robin, M., Archer, D., Garros, C., Gardès, L., Baylis, M., 2014. The threat of midge-borne equine disease: investigation of Culicoides species on UK equine premises. Vet. Rec. 174, 301.

Scheffer, E.G., Venter, G.J., Labuschagne, K., Page, P.C., Mullens, B.A., MacLachlan, N.J., Osterrieder, N., Guthrie, A.J., 2012. Comparison of two trapping methods for Culicoides biting midges and determination of African horse sickness virus prevalence in midge populations at Onderstepoort, South Africa. Vet. Parasitol. 185, 265-273.

Snedecor, G.W., Cochran, W.G., 1980. Statistical methods. Iowa State University Press.

Van Ark, H., Meiswinkel, R., 1992. Subsampling of large light trap catches of Culicoides (Diptera: Ceratopogonidae). Onderstepoort J. Vet. Res. 59, 183-189.

van der Rijt, R., van den Boom, R., Jongema, Y., van Oldruitenborgh-Oosterbaan, M.M.S., 2008. Culicoides species attracted to horses with and without insect hypersensitivity. Vet. J. 178, 91-97.

Venter, G.J., Groenewald, D., Venter, E., Hermanides, K.G., Howell, P.G., 2002. A comparison of the vector competence of the biting midges, Culicoides (Avaritia) bolitinos and C. (A.) imicola, for the Bryanston serotype of equine encephalosis virus. Med. Vet. Entomol. 16, 372-377. 
Venter, G.J., Labuschagne, K., Hermanides, K.G., Boikanyo, S.N.B., Majatladi, D.M., Morey, L., 2009. Comparison of the efficiency of five suction light traps under field conditions in South Africa for the collection of Culicoides species. Vet. Parasitol. 166, 299-307.

Venter, G.J., Labuschagne, K., Boikanyo, S.N., Morey, L., Snyman, M.G., 2011. The repellent effect of organic fatty acids on Culicoides midges as determined with suction light traps in South Africa. Vet. Parasitol. 181, 365-369.

Venter, G.J., Majatladi, D.M., Labuschagne, K., Boikanyo, S.N., Morey, L., 2012. The attraction range of the Onderstepoort 220V light trap for Culicoides biting midges as determined under South African field conditions. Vet. Parasitol. 190, 222-229.

Venter, G.J., Labuschagne, K., Boikanyo, S.N.B., Morey, L., 2014. Assessment of the repellent effect of citronella and lemon eucalyptus oil against South African Culicoides species. J. S. Afr. Vet. Assoc. 85. doi. org/10.4102/jsava.v85i1.992.

Viennet, E., Garros, C., Lancelot, R., Allène, X., Gardès, L., Rakotoarivony, I., Crochet, D., Delécolle, J.C., Moulia, C., Baldet, T., Balenghien, T., 2011. Assessment of vector/host contact: comparison of animalbaited traps and UV-light/suction trap for collecting Culicoides biting midges (Diptera: Ceratopogonidae), vectors of Orbiviruses. Parasit. Vectors. 4:119. doi: 10.1186/1756-3305-4-119., 119-4.

World Organisation for Animal Health, 2013. Infection with African horse sickness virus. In: Terrestrial Animal Health Code, OIE, Paris. Available at http://www.oie.int/fileadmin/Home/eng/Health standards/tahc/2010/chapitre 1.12.1.pdf. (accessed on 26 November 2013). 